Article

\title{
Moving with Touch: Entanglements of a Child, Valentine's Day Cards, and Research-Activism against Sexual Harassment in Pre-Teen Peer Cultures
}

\author{
Suvi Pihkala *, Tuija Huuki and Vappu Sunnari \\ Faculty of Education, University of Oulu, FI-90014 Oulu, Finland \\ * Correspondence: suvi.pihkala@oulu.fi
}

Received: 17 May 2019; Accepted: 22 July 2019; Published: 26 July 2019

check for updates

\begin{abstract}
In this paper, we respond to feminist new materialist scholars' calls to explore what research in the field of gendered and sexual violence can be, do, and become. This paper explores the microprocesses of change within the more-than-human child-card entanglements as part of our research-activist campaign addressing sexual harassment in pre-teen peer cultures. Drawing on one of our creative workshops, we generate three analytical readings that map touch. We focus, first, on the intra-action of bodies, objects, and abstractions that reconfigures painful experiences of harassment for recognition; second, on the affective charge in moments and movements of response and resistance; and third, on what else touch can become when it travels across time-space domains as part of our research-activism. Re-engaging with our research-activism, we propose that different kinds of touch converge into a sensing-feeling, inherently ethico-political, matter-realizing apparatus that reconfigures painful experiences of gendered and sexual harassment for recognition, response, and resistance. Connecting to feminist new materialist endeavors to envision and enact response-able research, we propose that 'moving with touch' helps us shed light on the microprocesses of change in generative ways-that is, in ways that recraft response-abilities and invite movement.
\end{abstract}

Keywords: Barad; children; creative methods; feminist new materialisms; research-activism; response-ability; sexual harassment; touch

\section{Introduction}

Sexual harassment was brought to renewed attention in 2017, prompted by the global '\#MeToo' movement. Having spent nearly 20 years exploring gender and sexual power plays among children in school settings, our research team-including Tuija, who was following the debate closely—was deeply affected by the discussion, which mostly ignored the ways sexual harassment connects to and permeates children's peer cultures. This combination of the 'hashtag feminism' (Mendes et al. 2018) against sexual harassment, the public debate, and our numerous research encounters with children marked the 'beginning in the middle' of our research-activist project. Theoretically, our research-activist approach was inspired by feminist new materialist and, in particular, 'phEmaterialist' work (e.g., Renold and Ringrose 2019), which have generatively merged feminist research with Deleuzian/Spinozian activist philosophies (e.g., Braidotti 2013) and the theories of micropolitics of change (Manning 2016; Massumi 2015) and affect (e.g., Blackman and Venn 2010) in order to envision ways of doing educational research capable of generating material changes in wider social spheres (e.g., Renold 2018; Ringrose et al. 2019).

The creative arts-based research-activist project, titled \#MeToo Postscriptum, that shaped the direction of this article, was designed and implemented by two of the authors-Tuija and Suvi-during the weeks before Valentine's Day in 2018. It emerged from Tuija's broader ongoing research and from a long continuum of research on gendered and sexual force relations by the authors (Huuki and Renold 
2016; Huuki et al. 2010; Holford et al. 2013; Pihkala and Huuki 2019; Sunnari et al. 2002; Sunnari 2010). Although it is often discussed only in relation to adults, research shows that sexual harassment—verbal, physical, material, emotional, or psychological sexual abuses of power-also affect young people in multiple, contradictory manners as normalized, everyday hetero-sexisms circulating within young peer cultures, media, and the wider social and cultural discourses (Gillander Gådin 2012; Holford et al. 2013; Meyer 2009; Renold 2013; Stein 2007; Sunnari 2010; Sunnari et al. 2002). However, young people are left with insufficient support for navigating these often contentious terrains of gender and sexuality (Renold 2013). Drawing inspiration from child-led activism in Wales (Renold 2018, 2019; Renold and Ringrose 2019), the \#MeToo Postscriptum campaign engaged children aged 10-12 years in creative workshops to explore their experiences of sexual harassment and to communicate those experiences to decisionmakers and the public.

In this paper, we return to and re-engage with one of the workshops, a workshop with a group of eight girls, ${ }^{1}$ and map the iterative intra-action of Valentine's Day cards, girls, experiences of past harassment, the research-activist campaign, and our own engagements and entanglements during the campaign. In re-engaging with the workshop, we employ touch as a steering concept that reanimates and enlivens within and through three analytically enacted moments at focus in this paper. Drawing on Barad's (2007) agential realism, with the first moment, we map more-than-human touch, focusing on the materiality of the workshop. We render visible how bodies, tables, movement, space, objects, postscripts, past, present, and research-activism intra-act, generating conditions of possibility for painful experiences to reconfigure for recognition. Then, we map what else touch can do, focusing on the affective charge in the moments and movements of response and resistance in the intra-action of past experiences, Valentine's cards, and a makeshift mailbox. Our third and final analysis maps what else touch can become as it gathers up and holds together across time-space domains, reaching towards, sticking to us, and traveling to wider change-making terrains. Mapping and moving with touch enable us to become open to the microprocesses and micropolitics of change and, as explored in this paper, to the ways in which painful experiences of harassment can be reconfigured for recognition, response, and resistance.

As invested and interested in co-constructing and theorizing response-able, everyday practices of change-making (Huuki 2019; Pihkala et al. 2018; Pihkala 2018), this paper contributes to the recent calls to envision response-able research and practice and to illuminate and theorize the microprocesses of change in our research endeavors (Ringrose et al. 2019; Renold 2018). 'Moving with touch' within our creative research-activism sheds light on the affordances of feminist new materialism-inspired approaches that are attuned to materiality, relationality, and becoming. We argue that our research-activism, predicated on creative, multimodal, more-than-human sense-abilities, fostered conditions in which unwanted, painful, silenced, and unaddressed experiences could be reconfigured for recognition, response, and resistance in ways that exceed the limits of humanistic and talk-based modes of engagement. Beginning from within entanglements and relationality, as opposed to pre-existing subjects and objects, enables us to attend to the material-discursive practices of body, object, gesture, movement, silence, voice, space, history, feeling, and touch and how these human and more-than-human elements intra-act, producing particular and contingent outcomes (Barad 2007). We

Informed by our long-term work with children around sensitive topics of gender and sexual harassment, the workshops were held in single-sex groups with the aim of ensuring safe possibilities for the participants to explore and communicate their experiences of their friendship and relationship cultures. Within the scope of this research, it was not possible to address the children's experiences of gender, but grounded in our long-term research on gender and power in child peer cultures, we were familiar with the specific context of our research-activism in Finland. In this context, issues of gender are sensitive, unaddressed, and often silenced, which make them difficult to address. The grouping by assumed gender aligned with the accustomed and dominant practices of the schools. It was based on our previous experiences of working in mixed-gender groups where the sensitivity and difficulty of the topic causes anxiety and dominant modes of gender expression become enforced. In order to work with and rework gender dichotomies, the groups were thus divided by assumed gender. However, our approach during our engagements with the children remained sensitive to the children's diverse gender expressions. 
maintain that working from within such entanglements enables elbow room for the unexpected and emergent and prompts us to not limit our inquiry to interpretations and instead invest in how research can be made to matter in the world (Ringrose et al. 2019). By thinking with theory and moving with touch, we make a speculative gesture towards theorizing what else touch can be, do, and become. Methodologically, mapping different kinds of touches causes them to converge into a sensing-feeling, inherently ethico-political, matter-realizing apparatus that yields a nuanced account of the intra-active moments when subtle shifts of change occur. It does so in generative ways- that is, in ways that recraft response-abilities and incite and invite movement.

\section{Each Intra-Action Matters: Envisioning the Microprocesses of Change in Research against Sexual Harassment in Pre-Teen Peer Cultures}

This paper connects to the expansive work inspired by feminist new materialist theories related to affect, materiality, and the relationality of human and more-than-human others (e.g., Barad 2007; Braidotti 2013; Dolphijn and van der Tuin 2012). This work has elicited heightened attunement and thoughtfulness in feminist research and social sciences more widely with respect to how bodies, objects, and discourses affect one another and are affected upon and how power, agency, and change, for example, are imagined (Fox and Alldred 2016; Ringrose et al. 2019). In phEmaterialist work, the reimagination of how gender, power, and sexuality matter in children's lives and, importantly, how change and transformation could be evoked (Renold and Ringrose 2019), has prompted-to use a term borrowed from Barad (2007) and Haraway (2008)—response-able research and pedagogy (Renold 2018; Ringrose et al. 2019; Taylor 2018). This call also acts as our motivation and inspiration to move with touch as we work to attune to and capture the subtle shifts of change within our research-activism.

In gauging such 'microprocesses of change' as they occur, we employ three pivotal threads from Barad's ethico-onto-epistemology. Barad (2007) introduced the idea of agential realism, proposing that the world and things 'come to matter' through agential cuts enacted through ongoing intra-action; that is, objects, abstractions, discourses, and even space and time do not pre-exist their relatings. This means that phenomena, such as gender and sexual harassment as the object of our inquiry and activism, too, must be understood to become intelligible through specific and contingent material-discursive arrangements or apparatuses of bodily production (Barad 2007). It is perhaps particularly in the matterings of gender and sexuality — and sexual harassment-where Barad's thinking works to make visible the agential force of discursive practices upon matter, and vice versa.

In this paper, intra-action, then, heightens our attention in relation to the dynamic ontological entanglements of human and more-than-human others-that is, how bodies, objects, movement, time, discourse, feelings, and gestures intra-act within and through the workshop. Furthermore, for Barad (2007), time does not work in a mode of linearity. This challenges the ways we understand change, which can no longer be perceived to follow from a past that once was but, rather, emerges through the iterative differentiating and reworking of a past that was never left behind and a future that is already present (Barad 2007). In this sense, each intra-action matters as a more-than-human and more-than-present encounter that holds the possibility 'to breathe life into ever new possibilities for living justly' (Barad 2007, p. x).

Considering the past experiences of pain, hurt, silence, and denial materializing for recognition through our research-activist apparatus against sexual harassment, Barad's thinking helps us attune to the intra-active entanglements anew. It helps us consider how, as we move, craft, and talk with the children, the intra-active entanglements of bodies, things, moments, and places come together and hold the possibility for making a difference in how sexual harassment matters. There is a breathtaking intimacy to this, as Barad (2014) writes. She brings the ethico-onto-epistemology of agential realism in touch with touch, stating that 'touching, sensing, is what matter does, or rather, what matter is: matter is condensations of response-ability' (Barad 2014, p. 161, italics removed). Indeed, the ethicality at the marrow of mattering - as captured in the hyphenated notion of 'response-ability' (Barad 2007; Haraway 2008) - is 'always already integral to the world's ongoing intra-active becoming and not-becoming' 
(Barad 2010, p. 265). It is an invitation and an obligation to enable and welcome the response of the other that inhabits 'each meeting' (Barad 2007).

Enriching our thinking about the intra-active entanglements of our research-activist encounters with touch and response-ability enables us to imagine the intra-activity at stake as materially crowded, affectively charged, and temporally rich-more-than-human and more-than-present-entanglements that are ethical from the get go. This thinking also reanimates 'our responsibility to be in touch' (Barad 2014) in our research-activist endeavors. As we maintain, how we co-compose the materials, creative practices, and human and more-than-human others matters. It matters to the ways we can help children identify and share with others their experiences and concerns related to sexual harassment and how we can foster possibilities for change in children's peer cultures. Indeed, Barad (2007, p. 89) asks us to 'tak[e] responsibility for the fact that our practices matter; the world is materialized differently through different practices'. This ethics as 'always-already' — response-ability (Barad 2007; Haraway 2008) — casts a challenge and obligation to 'cultivate the capacity to respond' (Haraway 2016, p. 7) and to reimagine the ethico-political potentiality in 'each meeting' in our attempt to both make inquiries into and co-compose conditions for co-flourishing.

\section{Method and Materials: Moving with Touch}

As part of the \#MeToo Postscriptum campaign, we organized and implemented 17 arts-based workshop sessions focusing on gendered and sexual harassment in pre-teen peer relations with a total of 150 children aged 10-12 years at schools in Finland. When organizing the workshops, we endeavored to create specific conditions that provide access to new ground and enable safe and creative intra-action (Barad 2007), so as to allow the participants to explore the ambivalences, contradictions, pains, and pleasures embedded in the gendered and sexual power relations of pre-teen peer cultures. Such conditions could be understood to constitute what Massumi (2015) calls 'enabling constraints', which propose a specific object of concern without, however, imposing preconceived notions about the final destination or outcome (Massumi 2015, p. 73). Enabling constraints, as we built upon them here, are carefully and purposefully made arrangements that cultivate conditions of response (Barad 2007; Haraway 2008) and that simultaneously mark our response-ability and accountability with respect to the becomings and not-becomings we help enact (Barad 2007).

The workshops involved activities related to the topic of sexual harassment. During the workshops, the children engaged in discussions and exploration of gendered and sexualized peer cultures and sexual harassment, created and drew Valentine's Day cards, and-if they chose to do so-wrote their own experiences of harassment in the postscripts of their cards. ${ }^{2}$ In addition to the workshops with the children, a pop-up stand was set up in a university café to allow student teachers and faculty members to partake the campaign by sharing their own childhood experiences of harassment. Through our research-activism, our aims were to generate data on children's experiences of sexual harassment in peer relations, ${ }^{3}$ communicate those experiences with children to wider audiences, and engage in political debate and social transformation. As part of the latter, after the workshops, the research team collected and sent the cards to every member of the Finnish Parliament and published excerpts from the notes and cards on the campaign website (Huuki and Pihkala 2018). The cards with the postscripts were intended to remind decisionmakers and the Finnish public of the need for systematic and consistent work to address sexual harassment, which affects not only adults but also children.

2 Occurring in advance of Valentine's Day, in our project, the \#MeToo became linked with the postscript section of a Valentine's Day card. The postscript worked to make visible the often-ignored nature and the silence regarding sexual harassment in pre-teen peer relations (Pihkala and Huuki 2019). Using the hashtag connected the project to the momentum afforded by the digital feminist activism of the \#MeToo movement (Mendes et al. 2018).

3 As part of our wider interest in investigating gender and sexual harassment in pre-teen peer cultures, the workshops were video-recorded, accumulating a total of $27 \mathrm{~h}$ of audio-visual recordings, 108 pages of transcripts, 15 pages of extended field notes, and 210 digitalized cards, of which the data for this paper involve $2 \mathrm{~h}$ and 36 min of audio-visual recordings from the workshop session in question. 
The human and more-than-human 'participants' of the campaign, such as the children, researchers, public, the decisionmakers, hands, chairs, tables, space, paper slips, pens, and arts and crafts; and the multiple modalities of the creative activities, such as the movement, crafting, speech, and writing, were understood as active and lively coplayers that came together in unexpected ways, as well as through our purposeful material, research-activist engagements that aimed to foster possibilities for the children to explore, address, and communicate their experiences of harassment.

The ethical considerations in relation to the project were ongoing before, during, and after our engagements with the children. As a 'spin off' and part of Tuija's ongoing research project, ${ }^{4}$ the \#MeToo Postscriptum campaign had obtained a statement from the Ethics Committee of Human Sciences at the University of Oulu, Finland and followed the policies of the schools in all matters of child protection. The workshop participants were recruited by contacting local schools and teachers interested in participating in the campaign. Information letters and consent forms were sent to the children and their legal guardians to be signed before participation. These letters included research-based information about gender and sexual harassment as the theme of the workshops, as well as information about the creative activities of the workshops and the campaign. They also included details about the use of the produced data and the possibility that the notes could be shared publicly and in research publications. These issues were discussed again with the children in the beginning of every workshop and additionally brought up whenever it seemed important. The activist orientation of the project was materially present in the creation of the Valentine's Day cards as the children themselves chose the members of parliament to whom their cards would be sent. The children were able to withdraw at any time or negotiate their own way of participating. For example, in some of the workshops, a few of the participants created cards that they did not want to share as part of the campaign. Those cards, or any cards that were ambiguous with respect to the children's consent, were excluded from the project.

Even when carefully considering ethics as part of our praxis, engaging children in research-activism involves ongoing response-ability with respect to the project as it unfolds and, for example, becomes public. We maintain that staying with the complexities and trouble (Haraway 2008, 2012, 2016) involved is important, as the entangled constellations of research and activism can produce processes of social change and transformation both within the lives of the children and within the wider terrains of social and educational policies and practices. Particularly in relation to sexual harassment in pre-teen peer cultures, which is a silenced and often unaddressed topic in schools, asking what matters to the children themselves is important. This, along with the premise of moving beyond merely stating the state of things in research on children's peer and relationship cultures (e.g., Huuki and Renold 2016; Renold 2018), guided our research-activist aim of helping children's experiences and voices to be heard, sensed, and felt so as to cultivate conditions for co-flourishing.

Building upon the project, in this paper, we generated an analysis focusing on and departing from one of the workshops. The data are comprised of video-recordings of a workshop with eight girls, postscript notes in which the children described their experience and collaborative reflections, and personal field notes taken by the research team members. When returning to the data, our aim was not so much to gain access to some undisputable truth about the workshop. Rather, the data helped us slow down - touch, sense, feel, and think — with the material, affective, and temporal entangledness involved. Over the course of the research process-while we were engaged in the workshops, cataloguing the research materials, publishing results, and returning to the data to write this paper-the data were iterated upon, continuously reassembled, and engaged in diffractive encounters that 'pulled in' different times and spaces.

Theory is 'put to work' (Dolphijn and van der Tuin 2012) in the three analytically enacted moments-that is, moments enacted by us through agential cuts (Barad 2007) within particular,

4 Project 'Gender-based violence in pre-teen relationship cultures: How history, place, affect and arts interventions matter', grant number 295000. 
contingent apparatuses of knowing (see also Lenz Taguchi and Palmer 2013). In this paper, such cuts were inspired by touch. Touch, as it unfolded for us here, carries resemblance to affect, as in 'being affected'. It is also a bodily practice and a mundane moment, for example, a pen touching a paper or a hand holding a paper slip. It is these affective and material tenors of touch that invited our attention. However, informed by and diffractively engaging with Barad's ethico-onto-epistemology, discussed previously in this paper, touch became removed from its human orbit. Thus, in the three analytical sections below, we map, first, more-than-human touch focusing on the materially crowded moments within the workshops. In the second section, our focus becomes drawn to the affective charge, and we explore what else touch as a mode of material feeling and thinking does in moments of response and resistance. In the final analytical section, we focus on what else touch can become as it gathers up and holds together across time-space domains as part of our research-activism. By mapping and moving with touch, we engage touch as a more-than-human and more-than-present player that intra-actively engages in the material-discursive practices within and through which sexual harassment 'comes to matter' and, as we explore, potentially a player that engenders conditions of possibility for subtle shifts, marking and making differences that matter in the hurt, silence, normalization, and denial of gender and sexual harassment by enabling the opening up to change and transformation towards co-flourishing.

\section{Research-Activist Encounters}

Below, we provide two accounts of the workshop. The accounts that we offer regarding the workshop must not be understood as a set of passive props but, rather, as a space-time entangled, affectively charged environment through and within which "what is "in" the foreground [is allowed] to acquire the shape that it does' (Ahmed 2010, pp. 239-40). In addition to describing the process of the workshop, we attune to the affective atmosphere (Stewart 2011) of the entanglements of the girls, the notes, movement, gestures, utterances, tables, chairs, and a makeshift mailbox, which will then be iterated in the following three analytical sections.

\subsection{The Workshop}

Similar to all the workshops, this workshop began with the children—eight girls in total—gathered in a circle of chairs. Two student teachers led the session, and Suvi participated. The student teachers read research-based statements about children's friendship and relationship cultures. Every time the participants agreed with the statement, they would stand up and switch seats. If they disagreed, or were unwilling or unable to take a stand, they would remain in place. The movement of one girl would easily stir movement in others. Sometimes, amidst bodies anchored in place to be, then again, on the move, discussions would unfold, causing us to linger on a topic for longer. Sometimes the topics would 'touch' the girls in a particular way, generating giggles or evoking stories-things the participants knew-about the ongoing relationships and romantic undercurrents within their peer relations. Those 'knowings' were sometimes voiced aloud and other times evident only in quick glances and smiles.

After the introduction to the topic of sexual harassment, the children were told about the research-activist campaign in more detail. They were instructed to craft Valentines' Day cards and, if they chose, to write about harassment they had experienced. Slips of paper with examples of some of the experiences disclosed in previous workshops with young people were put on the wall to prompt reflection. The notes described contentious and troubling touches and experiences with just a few words or a sentence, such as 'I have been slapped on the butt' or 'some boys in our class groped between girls' thighs with a ruler'.

Soon, the children began to collect materials to create their Valentine's Day cards. They gathered in a close group around one of the tables, chatting while they cut and folded the base of the cards and decorated them with drawings, tapes, stamps, glitter glue, and colors. When the cards were nearly ready and the participants began to contemplate their postscripts, the atmosphere shifted. If they had previously been gathered together, they seemed to scatter around the classroom, taking their newly 
crafted cards or empty slips of paper with them. For some of the children, it seemed difficult to think of something to write. This was expected, as not all children are caught up in same ways within the flows of peer and relationship cultures. Others hunched over their cards to shelter the affective, intimate, precarious space in which their experiences of harassment could be safely figured in words, written down, attached to the card, and eventually, slipped into a makeshift mailbox that was set up on one of the tables. Once placed in the mailbox, the notes and cards became part of the campaign. Some of them were curated for publishing online, and all of them were mailed to decisionmakers.

Gradually, the workshop session came to a close as the children left the classroom to get lunch, leaving the research team with the video recordings and the to-be-written research notes, the box of cards, and lingering affects-as we will elaborate upon below-which became reassembled within the broader research-activist apparatus of change-making regarding sexual harassment (Pihkala and Huuki 2019).

\subsection{A Girl with a Note}

In the latter half of the workshop, one girl caught Suvi's attention. At this point, the girl had already put her Valentine's Day card in the makeshift mailbox. She was one of the first participants to finish her card, but it did not include a postscript. Suvi remembered telling her that this was okay, as we could use such cards if someone else had several bits of stories to share. After completing the activity, she returned to the table where the others were still making their cards. Later, the girl began to meander around the room, walking from one table to the next and looking at the arts and crafts on the tables. We do not know what made her get up. Perhaps she was prompted by the fact that others had begun to find more private spaces to write, or perhaps the request to share experiences was made more insistent by the movement of bodies and shift in attention.

The girl halted by one of the tables, on which we had spread the notes that were previously hung on the wall to evoke discussion and reflection. She continued on but returned, pausing a bit longer by the table and whispering with another girl who had joined her there. Having looked at the notes for a while, the girl asked, 'Could one write something like that?' as she pointed to one of the notes. Suvi confirmed that she could and encouraged her to write something down if she still wanted to. Without saying much more, she took an empty slip of paper, returned to the table where she had been before, and began to write.

Moments later, the girl rose and walked to the makeshift mailbox, clutching the paper note, which was a little less than half the size of an A4 paper, close to her chest. Then, carefully doubling the paper without folding it, as if to keep her writing sheltered from others, she reached towards the makeshift mailbox and slipped her note in. She stepped to the side, looked back at the box and then walked away, hands casually in her jumper pockets, but it felt that what just happened was anything but casual.

After the workshop ended and we returned to our office to catalogue the cards, Suvi noticed that very same paper note, remembering the color and size. She remembered how the girl moved and halted at the table, the pointing, the card, and the curve of the note as she slipped it into the makeshift mailbox. All the details were pulled into that moment of recognition in the office. In her note, which, as part of the campaign, became entangled in the wider mosaic of experiences of harassment, the girl shared her painful experience from a few years back. Even though she sheltered the note from the eyes of her classmates, her slipping it into the makeshift mailbox, instead of the cards to be excluded from the project, gestured perhaps a political moment and movement of speaking out. We have not identified her experience in its singularity to ensure the girl's anonymity and because our focus is not on the experience described on the note but, rather, on the microprocesses of change and the subtle shifts that unfolded within and through the workshop. However, to respect this movement from silence to speaking out and speaking up, we have elsewhere made parts of the children's notes public (see Huuki and Pihkala 2018; Pihkala and Huuki 2019). 


\section{Past-Present Child-Card Entanglements of Response-Ability}

In this section, we map touch through the three analytically enacted moments. Each section, while entangled in nature, draws attention in specific ways to the productivity of the materiality, affective charge, and movements across time-space domains, as has been elaborated previously.

\subsection{Mapping Touch as More-Than-Human}

The design of the workshops-its different modalities and creative activities, as elaborated previously in this paper; the size and composition of the group; and the attention to more-than-human-were co-constructed so as to enable an atmosphere that 'touches' enough to enable 'responsiveness', that is, to help children explore, communicate, and address experiences of harassment that easily tend to be overcast by deafening silence when addressed in the primary school classroom. During the workshop, the girls gathered together, moved about, and stayed still while crafting with papers, pens, glitter glue, tapes, and colors. The notes laid out on the table carried traces of experiences of harassment, connecting the workshop to the collective history of felt and sensed touches of sexual harassment, be it physical, verbal, or otherwise, enfolded in this entanglement of child-bodies, notes, circles, tables, and the campaign. This intra-action of bodies, movements, and materials opening up to the unexpected and emergent is our first analytical cut.

For Barad (2014), touching is not centered on a human being, nor is it only affective. It is ontological and epistemological. Touching is what matter does. With this understanding of touch, the girls' movements and haltings, rummaging through the arts and crafts materials, writing and drawing, and re-membering (Barad 2010) past experiences fail to return to any one individual alone. Similar to the girl with the pointed finger tentatively asking if it could be 'something like that', the 'it' that comes to matter fails to return to an individual imagination or recognition only. Rather, within the intra-active entanglement of glitter glue, colors, paper slips, past-presents, and engaged bodies-sitting and moving in a circle and sharing experiences-it is not only the girls that touch and are touched. Thinking along the lines of Barad, both the girls and the matter-things, moments, and places-wander and wonder, curiously sensing and touching their im/possibilities, imagining, and inventing (Barad 2014, 2015).

In these moments of moving, halting, inciting, and inviting human and other than human bodies, matter, in its curious and imaginative 'self-touching' form (Barad 2014), reconfigures the girls' experiences for recognition in new ways. As bodies move within the circle of chairs; smiles appear; pens touch paper; bodies shift and sway in proximity and distance; gazes fall on notes; and past experiences make themselves present, touches subtly shift and rework hurtful, painful, unaddressed, and deep-seated experiences-even an experience from two years ago-for recognition, bringing something within reach that was not present before and perhaps reachable in a way that was not possible before.

\subsection{What Else Touch Can Do: The Affective Charge in Response and Resistance}

Our second analytical moment enacts a cut that draws focus to the affective charge in the intra-action of notes, bodies, and a makeshift mailbox. We return to the girl who clutched the note to her chest, carefully sheltering it from others, while also sharing it with others once she slipped it into the makeshift mailbox on the table. In the affectively charged mo(ve)ment of this 'held-shared' note from the intimacy of the girl's chest to the public space of the makeshift mailbox, being touched does something else; it reconfigures conditions of possibilities for touching in response.

When we returned to and re-engaged with this moment, we were caught by its force, as well as by our own visceral responses during the campaign. To elaborate, we had set up a pop-up stand in the university café to engage student teachers and faculty members in the campaign. The pop-up stand enabled passers-by to craft their own Valentine's Day cards and include their stories of harassment during childhood as postscripts. While sitting by a table in a busy café, we also wrote down our 
experiences. More than once, we found ourselves confronted with the difficulty and discomfort of doing so. An array of charges passed through our bodies: who sees me; who passes by; who sees the painful experience that comes to matter and is made to matter in this moment. We understand such charges as sensed-felt resonances and dissonance between the sensitivity of the experience, deep-seated anxieties related to our experiences of harassment and abuse, and the publicity both in that moment and inherent in the promise of the campaign, which invited us to explore intimate experiences and make them matter for others. It is through those embodied affective encounters and similar experiences shared by colleagues that we began to speculate about the ways the intra-active moment with the girl, the note, the moving-holding hands, and the makeshift mailbox was iteratively reconfigured from within the material and affective entanglements of the research-activist campaign.

As we sensed-felt while writing our own notes about harassment, in this moment, with the girl and the note and the materiality and affects of our research-activist workshop, touch was a sensed-felt resonance that intra-acted with the cards, the pens, the tables, the public space of the café, the passing bodies, and the rhythm of academic work and time and opened up towards a possible other world, generating new patterns of diffraction. Perhaps this touch is what Hemmings (2012) calls affective dissonance, the incongruity of ontology and epistemology and of being and knowing, which is felt as a visceral force, such as uncertainty, shame, upset, decidedness, and courage. This force marks the sense and feel of something coming within reach that was not there before in a way that invites engagement. For Hemmings (2012, p. 151), it is such dissonances that hold political possibility and the promise of movement. The movement within this entanglement of the girl—and, indeed, us as well-the note, and the embodied practice of holding the note close while reaching towards the makeshift mailbox unfolds as a mo(ve)ment of response, response-ability, and resistance.

We contend that what touch as a more-than-human player does in this moment is that it co-constitutes a site and space of response-a space enfolded with affects, things, places, and moments and unfolding towards resistance. Amplified by our own responses to writing down our pasts, we understand that the ability to be moved and affected to reach in resistance and to disturb the norms of what can be said, what can be resisted, what can be disrupted-be it the heterosexist normativities or intra-generational trauma (Huuki and Lanas 2019)—is frail and precarious. Yet, we maintain that the intra-active entanglement of the cards, the words written in the postscripts, the makeshift mailbox, and the promise and possibility of action enfolded in it allowed the past experience of hurt-the recognition-to reconfigure and to be not only known but to be resisted.

\subsection{What Else Touch Can Become: Gathering Up and Holding Together/Apart across Time-Space Domains}

As we curated the cards for the campaign website, the note became reanimated, making sense-able the response-ability and accountability it crafted by inviting and obliging us to care about it and to be careful with it without certainty if the 'it' is the card, the 'data', the words written in the cards, the girl who wrote it, the upsetting experience described in the note, the hurt embedded within it, or perhaps the academic writing about 'it'. The intra-active entanglement of the child, cards, creative practice, research, and activism diffracts, sending out ripples that, no matter how small, hold the potentiality for 'consequential meanings' (Haraway 1997). This touch of the girl's response held its grip when we selected excerpts from the cards to publish on the campaign website and when the upset and hurt became realigned in the title of a news article in a national newspaper, (re-)making us as (modest) witnesses, complicit, and response-able (Haraway 1997, 2008). For Haraway (2008, p. 36), this is exactly what touches can do: they shape and ramify accountability, where '[a]ccountability, caring for, being affected, and entering into responsibility are not ethical abstractions' but mundane practices of becoming with.

As explored earlier in this paper, due to the affective charge sensed and felt by us while writing notes about our childhood experiences of harassment, there was a familiarity that resonated from the entanglement of the girl, the note, and the makeshift mailbox. It would be rather easy to foreground how we were emotionally affected by the girl's story and how the touch-affect jumps back and forth, 
first during the workshop and again in the office, from us to the girl and from the girl to us or to all those 'others' who we can imagine being touched. Perhaps it was the familiarity in the dissonance of holding close and disclosing that we recognize, of keeping hidden but wanting to seize the opportunity to disrupt conventional silences around touches that hurt-to reach and touch in resistance.

The sense of familiarity moves us to speculate that we were not merely slightly grazed by this one experience and the touches surrounding it; rather, in being touched by the girl's experience, matter, time, and space realigned and reinvented itself in a reiterative practice of reconfiguring (Barad 2007). In effect, we argue that touch, as mapped here, reaches and holds across and beyond space-time domains. Our adult researcher bodies hold and carry 'impressions' of our own past touches-such as a re-membered slap-which, as Barad (2010) notes, never left us. New touches stick to us, such as the touch-affect from the girl. These touches did not just stick and jump but became more-than-human and more-than-present players in this research-activist constellation. Each touch invents new matter forms by gathering up and holding together/apart the past and present (Barad 2010), the researcher-adult, the researcher-child, the girl with the note, the researcher with a note, and, perhaps, also the pre-teen girls that have been and will be affected by sexual harassment in their peer relations.

Neither the girl being touched nor we, who were being touched by the girl-being-touched, were contained in the 'touch-encounter'. Thinking along the lines of Barad (2007), we enter into relations of response not because of what touches us from afar but because there were never separate parts to begin with. Indeed, response-abilities are not crafted from a graze. In other words, they are not created by 'knowing' the girl's troubling experience but from the capacity of us be(com)ing (with) in touch (see Pihkala 2018), that is, the capacity of touch to draw times, spaces, and matter into new relations, inviting touch in response.

\section{Microprocesses of Change and the Possibilities of Moving with Touch}

Knowing what we know and feeling what we feel, any of the notes from our research-activist campaign might be swarming with as many affects, times, and embodied materiality as surround the workshop or the girl with the note as discussed in this paper. Nonetheless, in this particular entangled practice of engagement, this girl touched us, took hold of us, and pulled us to move with touch in response. Furthermore, slipped into the makeshift mailbox, the girls' notes, 'crafted from and carrying their experience' (Renold 2018, p. 38), became 'knotted' with the wider change-making apparatus against sexual harassment: the campaigns, personal accounts, public debate, and (digital) feminist activism that have enabled young people to speak out against 'rape culture' in new ways (Mendes et al. 2018). To claim how the campaign mattered to the girls—or any of the participants-would be speculative at best. However, the children's need to address and explore their concerns related to gender and sexual peer cultures has been tangible time and time again as the children have voiced the need for safe spaces where sensitive topics could be discussed. For this, engaging children with creative activities can enable subtle shifts and minor gestures (Manning 2016) towards sustainable alternatives in peer relations when imagined worlds are materialized through crafting, drawing, and writing.

The research-activist encounters of our creative workshop against sexual harassment in pre-teen peer cultures is materially rich, affectively charged, and temporally entangled. In gauging the microprocesses of change as they occur, we mapped touch and explored what else touch(es) can do. As we mapped in our analysis, the entanglement of the group of girls, Valentine's Day cards, past, and present involved different kinds of touches in different registers, such as embodied, corporeal touches of gropes and slaps; verbal touches; material touches of pen on paper; present touches that leave impressions and linger; past touches that carry the residues of the past; the touch-affects that slip through cognition shooting straight through our bodies in resonances and dissonances; and the onto-epistemological touches that sense the virtual in an exploration of the possible, quantum, and queer touches, as discussed by Barad (2015). Just as touch seems to settle in senses, it is already on the move, reaching, holding, and gathering. The childhood slaps and gropes reached the Valentine's Day cards in a café, the child-bodies reached a researcher-child, a finger reached for a pile of notes, a hand 
reached for the makeshift mailbox, the mailbox reached us, and the otherwise-made-possible reached the body-in-reach.

We maintain that there is a particular benefit in thinking of the microprocesses of change with touch. For one, mapping touch, as we did here, enabled us to capture the subtle shifts in the children's unaddressed, silenced, normalized, hurtful experience. Rather than being here and there-or this or that-touches intra-acted within and through the workshop as more-than-human and more-than-present players and converged into an inventive, imaginative, sensing-feeling, matter-realizing apparatus, which activated recognition of, response to, and resistance against sexualized and gendered force relations. Thinking along the lines of Barad (2014), this is what touch - when thought of in the quantum mode—can do: sense and feel and gather up and hold together/apart (Barad 2014, 2015). Drawing matter into new relations, characterized by indeterminacy waiting to remake momentary alliances, touch reworks and recrafts response-abilities (Barad 2014; Haraway 2008).

For another, the ethico-political tone of touch is intimate and entangled. With touch, it is impossible to keep one's distance or disavow how we are touched and how the ways we touch shape and co-constitute the conditions of possibilities for touching in response and resistance to the 'other'. Our experience of being touched by the girls' experiences and our research-activism, which brought disparate matters and modalities together, generating the imaginative, creative, sensing-feeling apparatus, knotted us in webs of manifold more-than-human and more-than-present touches that diffractively reconfigured ever-new possibilities for change. For us, as researchers and activists, thinking with touch engages theory in ways that moves and transforms relations, engagements, and accountabilities. We contend that this is the way feminist new materialist touch works: it is not only 'put to work' (Dolphijn and van der Tuin 2012) but becomes enacted when objects, bodies, abstractions, and moments intra-act-how they sense and feel, imagine and invent, reach in response, gather up, and hold together.

Finally, thinking about our research-activism with touch draws attention to the affective, material, and temporally entangled encounters that contest and remake what is possible, producing 'differences that matter'. While the anatomy of these encounters cannot be laid bare, engaging them with new conceptual companions-as we did in this paper-can help enrich the ways we think, feel, and practice research in ways that can make a difference. Indeed, moving with touch aligns with more-than-theoretical approaches to what research can do. It speaks to the power and potentiality of and responsibility to participate in co-composing research encounters that invite and enable response to the other. This demands that we carefully co-compose thick, material, and affective encounters that invite and enable children, researchers, and others to sense, feel, think, imagine, wander, and wonder with - to become with (Haraway 2008)—the postscripts, cards, pens, papers, space, and time and, through subtle shifts, make new kinds of, more livable, worlds.

To close with a tentative gesture, mapping what touches do encouraged us to also imagine a touch that is of a world-making kind (Haraway 2008) and one that creates accountability and response-ability (Barad 2014). With this, we maintain that moving with touch is an open-ended endeavor but one imbued with conviction. Touch not only brings other beings, spaces, and times together (or to matter) but also leaks out to other worlds by reaching in response and resistance, touching and carefully holding those other visions, worlds, and possibilities. At the same time, we are not left untouched; as we reach out, response and resistance stick to us.

Author Contributions: Conceptualization, S.P. and T.H.; Investigation, S.P. and T.H.; Methodology, S.P. and T.H.; Writing—original draft, S.P.; Writing—review \& editing, T.H. and V.S.

Funding: This research was partly funded by Academy of Finland, grant number 295000.

Acknowledgments: We would like to acknowledge communal and visual artist Anna Koivukangas for suggesting the title \#MeToo Postscriptum to us when we were planning the project. We wish to thank the student teachers involved in the workshops as well as the teachers and most importantly the children and schools without whom the \#MeToo Postscriptum would not have been possible. 
Conflicts of Interest: The authors declare no conflicts of interest.

\section{References}

Ahmed, Sara. 2010. Orientations Matter. In New Materialisms: Ontology, Agency, and Politics. Edited by Diana Coole and Samantha Frost. Durham: Duke University Press, pp. 234-57.

Barad, Karen. 2007. Meeting the Universe Halfway: Quantum Physics and the Entanglement of Matter and Meaning. Durham: Duke University Press.

Barad, Karen. 2010. Quantum Entanglements and Hauntological Relations of Inheritance: Dis/continuities, Spacetime Enfoldings, and Justice-to-Come. Derrida Today 3: 240-68. [CrossRef]

Barad, Karen. 2014. On Touching-The Inhuman That Therefore I Am (v1.1). In The Power of Material-The Politics of Materiality. Edited by Susanne Witzgall and Kerstin Stakemeier. Zurich: Diaphanes, pp. 153-64.

Barad, Karen. 2015. Transmaterialities: Trans*/matter/realities and Queer Political Imaginings. GLQ: A Journal of Lesbian and Gay Studies 21: 387-422. [CrossRef]

Blackman, Lisa, and Couze Venn. 2010. Affect. Body and Society 16: 7-28. [CrossRef]

Braidotti, Rosi. 2013. The Posthuman. Cambridge: Edinburgh University Press.

Dolphijn, Rick, and Iris van der Tuin. 2012. New Materialism: Interviews E Cartographies. Ann Arbor: Open Humanities Press. [CrossRef]

Fox, Nick J., and Pam Alldred. 2016. Sociology and the New Materialism. Theory, Research, Action. Los Angeles: Sage. Gillander Gådin, Katja. 2012. Sexual Harassment of Girls in Elementary School a Concealed Phenomenon within a Heterosexual Romantic Discourse. Journal of Interpersonal Violence 27: 1762-79. [CrossRef] [PubMed]

Haraway, Donna. 1997. Modest_Witness@Second_millenium.FemaleMan@_Meets_OncoMouse ${ }^{\mathrm{TM}}$. London: Routledge. Haraway, Donna. 2008. When Species Meet. Minneapolis: Minnesota University Press.

Haraway, Donna. 2012. Awash in Urine: DES and Premarin ${ }^{\circledR}$ in Multispecies Response-Ability. WQS: Women's Quaterly 1-2: 301-17. [CrossRef]

Haraway, Donna. 2016. Staying with the Trouble: Making Kin in the Chthulucene. Durham: Duke University Press.

Hemmings, Clare. 2012. Affective Solidarity: Feminist Reflexivity and Political Transformation. Feminist Theory 13: 147-61. [CrossRef]

Holford, Naomi, Emma Renold, and Tuija Huuki. 2013. What (Else) Can a Kiss Do?: Theorizing the Power Plays in Young Children's Sexual Cultures. Sexualities 6: 710-29. [CrossRef]

Huuki, Tuija, Sari Manninen, and Vappu Sunnari. 2010. Humour as a Resource and Strategy for Boys to Gain Status in the Field of Informal School. Gender and Education 22: 369-83. [CrossRef]

Huuki, Tuija, and Emma Renold. 2016. Crush: Mapping Historical, Material and Affective Force Relations in Young Children's Hetero-Sexual Playground Play. Discourse: Studies in the Cultural Politics of Education 37: 754-69. [CrossRef]

Huuki, Tuija, and Suvi Pihkala. 2018. \#MeToo Postscriptum. Available online: https://metoopostscript.wordpress. com/ (accessed on 5 July 2019).

Huuki, Tuija, and Maija Lanas. 2019. Sámi Child-Adult/past-Present Entanglements in a Painful Lecture in University. In Social, Material and Political Constructs of Arctic Childhoods: An Everyday Life Perspective. Edited by Pauliina Rautio and Elina Stenvall. Singapore: Springer, pp. 135-48.

Huuki, Tuija. 2019. Collaging the Virtual: Gender Materialisations in the Artwork of Pre-Teen Children. Childhood. [CrossRef]

Lenz Taguchi, Hillevi, and Anna Palmer. 2013. A more 'livable' school? A diffractive analysis of the performative enactments of girls' ill-/well-being with(in) school environments. Gender and Education 25: 671-87. [CrossRef]

Manning, Erin. 2016. The Minor Gesture. Durham: Duke University Press.

Massumi, Brian. 2015. Politics of Affect. Cambridge: Polity.

Mendes, Kaitlynn, Jessica Ringrose, and Jessalynn Keller. 2018. \#MeToo and the Promise and Pitfalls of Challenging Rape Culture through Digital Feminist Activism. European Journal of Women's Studies 25: 236-46. [CrossRef]

Meyer, Elizabeth J. 2009. Gender, Bullying, and Harassment: Strategies to End Sexism and Homophobia in Schools. New York: Teachers College Press.

Pihkala, Suvi. 2018. Touchable Matters: Reconfiguring Sustainable Change Through Participatory Design, Education and Everyday Engagement for Non-Violence. Doctoral dissertation, University of Oulu, Oulu, Finland, April 6. Available online: http://urn.fi/urn:isbn:9789526218434 (accessed on 25 July 2019). 
Pihkala, Suvi, Tuija Huuki, Mervi Heikkinen, and Vappu Sunnari. 2018. Reconfigurings of Non-Violence as a Matter of Response-Ability and Sustainability. NORA-Nordic Journal of Feminist and Gender Research 26: 167-81. [CrossRef]

Pihkala, Suvi, and Tuija Huuki. 2019. How a Hashtag Matters-Crafting Response(-Abilities) through Creative Research-Activism Addressing Sexual Harassment in Pre-Teen Peer Cultures. Unpublished manuscript.

Renold, Emma. 2013. Boys and Girls Speak Out: A Qualitative Study of Children's Gender and Sexual Cultures (Ages 10-12). Cardiff: Cardiff University, Available online: http://www.childcom.org.uk/uploads/publications/411. pdf (accessed on 25 July 2019).

Renold, Emma. 2018. "Feel What I Feel": Making Da(r)ta with Teen Girls for Creative Activisms on How Sexual Violence Matters. Journal of Gender Studies 27: 37-55. [CrossRef]

Renold, Emma. 2019. Becoming AGENDA: Co-creating of a youth-activist resource to address gendered and sexual violence with a run-a-way pARTicipatory praxis. An unpublished manuscript.

Renold, Emma, and Jessica Ringrose. 2019. JARing: Making phematerialist research practices matter. MAI: Feminism and Visual Culture, May 16. Available online: https://maifeminism.com/introducing-phematerialismfeminist-posthuman-and-new-materialist-research-methodologies-in-education/ (accessed on 25 July 2019).

Ringrose, Jessica, Katie Warfield, and Shiva Zarabadi. 2019. Introducing Feminist Posthumanisms/New Materialisms \& Educational Research: Response-able Theory-Practice-Methodology. In Feminist Posthumanisms, New Materialisms, and Education. Edited by Ringrose Jessica, Katie Warfield and Shiva Zarabadi. London: Routledge, pp. 1-15.

Stein, Nan. 2007. Locating a Secret Problem: Sexual Violence in Elementary and Secondary Schools. In Gender Violence: Interdisciplinary Perspectives, 2nd ed. Edited by Laura O'Toole, Jessica R. Schiffman and Margie L. Kitter Edwards. New York: New York University Press, pp. 323-32.

Stewart, Kathleen. 2011. Atmospheric Attunements. Environment and Planning D: Society and Space 29: 445-53. [CrossRef]

Sunnari, Vappu. 2010. "I Cannot Speak about It". Physical Sexual Harassment as Experienced by Children at School in Northern Finland and Northwest Russia. Saarbrücken: VDM Verlag.

Sunnari, Vappu, Jenny Kangasvuo, and Mervi Heikkinen, eds. 2002. Gendered and Sexualised Violence in Educational Environments, 2nd ed. Oulu: Oulu University Press, Available online: http://herkules.oulu.fi/isbn9514268946/ isbn9514268946.pdf (accessed on 25 July 2019).

Taylor, Carol A. 2018. Each Intra-Action Matters: Towards a Posthuman Ethics for Enlarging Response-Ability in Higher Education Pedagogic Practice-Ings. In Socially Just Pedagogies: Posthumanist, Feminist and Materialist Perspectives in Higher Education. Edited by Rosi Braidotti, Vivienne Bozalek, Tamara Shefer and Michalinos Zembylas. London: Bloomsbury, pp. 81-96.

(C) 2019 by the authors. Licensee MDPI, Basel, Switzerland. This article is an open access article distributed under the terms and conditions of the Creative Commons Attribution (CC BY) license (http://creativecommons.org/licenses/by/4.0/). 